\title{
Examining the Effectiveness of Video Instruction on Teaching Daily Living Skills to Adolescents and Young Adults With Intellectual Disability
}

\author{
Annemarie L. Horn ${ }^{1}$ \\ ${ }^{1}$ Department of Communication Disorders and Special Education, Old Dominion University, USA \\ Correspondence: Annemarie L. Horn1, Ph.D., Department of Communication Disorders and Special Education, Old \\ Dominion University, USA. E-mail: ahorn@odu.edu
}

Received: March 9, 2018

Accepted: March 27, 2018

Online Published: April 3, 2018

doi:10.5430/irhe.v3n2p6

URL: https://doi.org/10.5430/irhe.v3n2p6

\begin{abstract}
Independently performing essential daily living skills enables individuals to become more self-sufficient adults. Those with intellectual disability (ID) tend to require direct instruction and repetition to successfully aquire everyday tasks. Many adults with ID continue to show deficits in this domain, affecting independent living abilities (Luftig \& Muthert, 2005). Video-based instruction holds promise in increasing autonomous functioning while decreasing reliance on staff. This review of the literature examines the effectiveness of using video instruction (VI) to teach daily living skills to adolescents and young adults with ID. Acquisition, generalization, and maintenance of target skills are examined across the literature. A total of 12 empirical articles on VI were reviewed, all published between 2006-2017. Findings support the use of VI when teaching daily living skills to adolescents and adults with mild or moderate ID. Implications for research and practice are offered.
\end{abstract}

Keywords: daily living skills, independent functioning, intellectual disability, video modeling, video prompting

\section{Introduction}

Transition planning has become a federally mandated integral component of Individual Education Program (IEP) development in secondary school (IDEA, 2004). IDEA 2004 stipulates that such planning must take place no later than age 16 for all students with an identified disability (Li, Bassett, \& Hutchinson, 2009; Luftig \& Muthert, 2005). With a focus on post-secondary outcomes, including continuing education, employment, and independent and community living, effective transition services must meet individual student needs as adolescents prepare for their postsecondary future ( $\mathrm{Li}$ et al., 2009). While the path toward adulthood is unique to each student, it is imperative to recognize and address student strengths and needs during the transition process and beyond (Bouck, 2014). Individuals with intellectual disabilities (ID) face challenges with postsecondary success, even in comparison to counterparts with other identified disabilities (e.g., learning disabilities, emotional disabilities; Grigal, Hart, \& Migliore, 2011). With the greatest discrepancy in the areas of employment and independent living (Luftig \& Muthert, 2005), less than one-third of adults with mild ID live independently (Bouck, 2014).

Self-sufficient living requires individuals to autonomously perform and generalize daily living skills (e.g., functional and domestic skills), and being deficient in this domain may negatively affect societal participation as well as one's quality of life (Carnahan, Hume, Clark, \& Borders, 2009; Sigafoos et al., 2005; Taber-Doughty, Bouck, Tom, Jasper, Flanagan, \& Bassette, 2011). Food preparation is among one of the many vital skills needed for independent living (Ayres \& Cihak, 2010; Graves et al., 2005; Mechling, 2008). Additionally, washing dishes, cleaning, and folding laundry are all examples of essential functional daily living skills (Gardner \& Wolfe, 2015; Mechling, Ayers, Bryant, \& Foster, 2014; Van Laarhoven \& Van Laarhoven-Myers, 2006). While typically developing individuals tend to display more of a natural progression of skill acquisition as they reach developmental milestones, those with ID require frequent repetition and practice (Ayres \& Cihak, 2010).

Independently performing daily living skills enables individuals to take initiative while becoming empowered and gaining confidence in their functional abilities. Therefore, it is essential to include functional skill attainment as an instructional necessity for individuals with ID (Ayres \& Cihak, 2010; Graves, Schuster, \& Kleinert, 2005; Li et al., 2009). Empirical literature supports several procedural applications used to teach daily living skills to the ID 
population (e.g., time delay, system of least prompts, most-to-least prompts), yet each method relies on trained staff for implementation (Ault, Gast, \& Wolery, 1988; Gast, Ault, Wolery, Doyle, \& Belanger, 1988; Swain, Lane, \& Gast, 2015). Conversely, video-based instruction has been used across learning domains to decrease reliance on staff while promoting independent, autonomous functioning through use of natural prompts (Mechling, Ayres, Bryant et al., 2014; Mechling, Gast, \& Seid, 2010; Van Laarhoven \& Van Laarhoven-Myers, 2006). Moreover, video technology has been reported to be an effective and efficient method to use when teaching daily living skills to individuals with disabilities (Graves et al., 2005; Van Laarhoven \& Van Laarhoven-Myers, 2006; Van Laarhoven, Zurita, Johnson, Grider, \& Grider, 2009). Applied research on video-based instruction commonly refers to video modeling (VM) and video prompting (VP) procedures (Cannella-Malone, Sigafoos, O'Reilly, de la Cruz, Edrisinha, \& Lancioni, 2006). Through video observation, learners are provided with instructional consistency, predictability, repetition, and opportunities to apply acquired skills in the natural environment (Banda, Dogoe, \& Matuszny, 2011; Gardner \& Wolfe, 2015). However, notable methodological differences exist between VM and VP procedures that warrant further clarification.

\subsection{Video Modeling}

VM takes place when a learner watches a video clip of a model completing a target task in its entirety at the onset of each instructional session (Goodson, Sigafoos, O'Reilly, Cannella, \& Lancioni, 2007). Subsequently, he or she [the learner] performs the corresponding behavior in the classroom or natural environment (Alberto, Cihak, \& Gama, 2005; Cannella-Malone et al., 2006). A newly researched variation of VM, continuous video modeling (CVM), is consistent with the previous definition, yet the video plays in a repetitive, "looping" format (Mechling, Ayres, Bryant et al., 2014). Thus, enabling learners to view the model continuously while applying the learned skills in the natural environment. Several viewpoint variations of models exist within all VM strategies. The first variation of VM, video self-modeling, involves learners viewing themselves as they complete the desired skill (Van Laarhoven et al., 2009). Using self-models may highlight individual strengths and promote successful task completion. Nonetheless, this approach typically requires extensive editing, making the creation of recordings time consuming, and videos are limited to being used by only one participant. The second variation, subjective models, uses a first-person viewpoint for the duration of the video clip. This approach is unique in that no model is present. Rather, learners view task completion from the same perspective they would while completing the skillset themselves (Van Laarhoven et al., 2009). The third variation, other models, is commonly used for VM purposes (Cannella-Malone et al., 2006; Van Laarhoven et al., 2009; Van Laarhoven \& Van Laarhoven-Myers, 2006). This method is based on observational learning, where the student views a video clip of a typically developing peer or staff member successfully completing the target skill (Van Laarhoven et al., 2009). Regardless of viewpoint variations, all VM perspectives consistently present the target skill in its entirety to the learner, which differs from other video-based instructional procedures.

\subsection{Video Prompting}

VP is another video-based instructional method that utilizes technology to present a video clip of an individual completing a skill. Videos are unique in that they are filmed from the subjective perspective with a simple (e.g., one sentence) directive for each sequential step (Mechling \& Stephens, 2009). VP differs from VM in that each step of the target skill is observed individually, rather than showing the skillset in its entirety (Cannella-Malone et al., 2006; Goodson et al., 2007; Sigafoos et al., 2006). Thus, VP enables learners to focus on mastering each individual component of a task explicitly prior to previewing the succeeding step (Cannella-Malone, 2006; Gardner \& Wolfe, 2015; Mechling \& Stephens, 2009). Used as an antecedent prompt, the learner observes a brief video clip before performing the corresponding step of the task (e.g., opening a microwave) in a classroom or natural environment (Goodson et al., 2007). He or she may repeatedly review the video clip, if needed, ensuring comprehension of the behavioral expectation. The projected learner outcome is to rely on VP during initial task acquisition, while simultaneously decreasing reliance on staff (Mechling, 2008).

There is a need for individuals with ID to increase independent daily living abilities (Bouck, 2014; Luftig \& Muthert, 2005; Van Laarhoven \& Van Laarhoven-Myers, 2006), and video-based instructional procedures are promising in shifting stimulus control from staff to learner (Mechling, 2008). Thus, the purpose of this review is to examine empirical literature evaluating video-based instruction (e.g., VM, VP) used to assist adolescents and adults with ID when completing essential daily living skills. Specifically, this review of the literature addresses the following question: how does the use of video instruction (e.g., VM, VP) affect acquisition, generalization, and maintenance of daily living skills among adolescents and adults with mild or moderate ID. 


\section{Method}

A review of the literature was conducted on the effectiveness of using video instruction (e.g., VM, VP) to teach daily living skills to adolescents and adults identified with mild or moderate ID. Empirical, peer-reviewed journal articles covering an eleven-year period (2006-2017) were included in the search. Preliminary search procedures consisted of using the Educational Resources Information Center (ERIC) and EBSCOhost databases, which were accessed through the web-based university website. Additionally, Google Scholar was used as an online resource during article retrieval. Full and truncated versions of keywords included video instruction, video modeling, video prompting, daily living skills, domestic skills, life skills, independent living, and intellectual disabilities. Finally, an ancestral search was made of reference lists of all identified peer-reviewed articles. Published studies meeting initial inclusion criteria were electronically retrieved for further analysis.

Documented preliminary search procedures yielded a total of 23 cumulative peer-reviewed articles. Based on the title, keywords, and publication year, article selection was narrowed to 16 studies. Next, abstracts were reviewed, further narrowing the search to include a total of 14 articles. Subsequent to full text analysis, final article selection was made based on the following criteria: (a) study participants consisted of adolescents or adults identified as having mild or moderate ID; (b) dependent variables measured the effectiveness of using a specific form of video technology (e.g., VM or VP) during skill acquisition, or compared various instructional methods, with at least one procedure consisting of VM or VP; and (c) acquisition of at least one daily living skill was measured in each study.

The effectiveness of VI has been measured in studies that include participants with diverse learning needs, and skill acquisition has been evaluated across learning domains. Articles were excluded from this review if: (a) study participants were younger than age 12; (b) did not have a diagnosis of mild or moderate ID (e.g., severe ID, autism without a dual diagnosis of ID); (c) task acquisition did not fall in the realm of daily living skills (e.g., employment skills, academics, community functioning, safety skills); and (d) instructional procedures did not consist of at least one form of video instruction (e.g., static picture prompts only).

Overall, 12 peer-reviewed articles met the inclusionary criteria for this review. All studies demonstrated experimental control through a single-subject research design. Table 1 presents a detailed summary of the analyzed variables included in this review.

Table 1. Content across studies

\begin{tabular}{|c|c|c|c|c|c|}
\hline Reference & Purpose & Participants & Measured Skillset & Design & Results \\
\hline $\begin{array}{l}\text { Ayres \& } \\
\text { Cihak (2010) }\end{array}$ & $\begin{array}{l}\text { Determine if students acquire } \\
\text { and generalize a life skill } \\
\text { sequence when taught using } \\
\text { CBVI }\end{array}$ & $\begin{array}{l}\text { Three adolescents with } \\
\text { moderate ID }\end{array}$ & $\begin{array}{l}\text { 1. Making a sandwich } \\
\text { 2. Using a microwave } \\
\text { 3. Setting the table }\end{array}$ & $\begin{array}{l}\text { Multiple probe } \\
\text { design across } \\
\text { behaviors and } \\
\text { replicated across } \\
\text { students }\end{array}$ & $\begin{array}{l}\text { Participants acquired target skills when } \\
\text { using CBVI. Task maintenance } \\
\text { decreased at 6- and } 12 \text {-week probes. } \\
\text { Tasks were relearned following a } \\
\text { training session }\end{array}$ \\
\hline $\begin{array}{l}\text { Cannella-Mal } \\
\text { one et al. } \\
(2006)\end{array}$ & $\begin{array}{l}\text { Compare acquisition rates } \\
\text { between two instructional } \\
\text { methods, VP and VM, when } \\
\text { learning two new domestic } \\
\text { skills }\end{array}$ & $\begin{array}{l}\text { Six adults with a } \\
\text { primary diagnosis of } \\
\text { mild or moderate ID. } \\
\text { Secondary diagnoses } \\
\text { included mood disorder } \\
\text { (1); Autism (4); and } \\
\text { Asperger's (1) }\end{array}$ & $\begin{array}{l}\text { 1. Setting the table } \\
\text { 2. Putting away } \\
\text { groceries }\end{array}$ & $\begin{array}{l}\text { Multiple-probe } \\
\text { across subjects } \\
\text { design with an } \\
\text { alternating } \\
\text { treatments design }\end{array}$ & $\begin{array}{l}\text { More effective skill acquisition } \\
\text { occurred when using the VP technique } \\
\text { in comparison to VM, across all } \\
\text { participants. VM was found to not be } \\
\text { effective (e.g., low percentage of } \\
\text { corrects, no gain in acquisition). }\end{array}$ \\
\hline $\begin{array}{l}\text { Gardner \& } \\
\text { Wolfe (2015) }\end{array}$ & $\begin{array}{l}\text { Assess effectiveness of a VP } \\
\text { with error correction } \\
\text { procedure on teaching daily } \\
\text { living skills to individuals } \\
\text { with ID }\end{array}$ & $\begin{array}{l}\text { Four adolescents with } \\
\text { mild or moderate ID. } \\
\text { Two had additional } \\
\text { diagnoses of OHI; one } \\
\text { participant had an } \\
\text { autism diagnosis }\end{array}$ & $\begin{array}{l}\text { 16-step task analysis } \\
\text { for washing dishes }\end{array}$ & $\begin{array}{l}\text { Multiple baseline } \\
\text { across participants } \\
\text { design }\end{array}$ & $\begin{array}{l}\text { All participants successfully acquired } \\
\text { dishwashing skills using VP in less } \\
\text { than } 10 \text { intervention sessions. } 3 \\
\text { participants maintained skills at the } \\
\text { 1-week follow-up, while } 1 \text { student } \\
\text { maintained skills } 2 \text { weeks } \\
\text { post-intervention. }\end{array}$ \\
\hline $\begin{array}{l}\text { Goodson et } \\
\text { al. (2007) }\end{array}$ & $\begin{array}{l}\text { Determine if adding } \\
\text { video-based error correction } \\
\text { would affect skill acquisition } \\
\text { for learners who were }\end{array}$ & $\begin{array}{l}\text { Four adults with } \\
\text { moderate ID }\end{array}$ & Setting the table & $\begin{array}{l}\text { Multiple baseline } \\
\text { design }\end{array}$ & $\begin{array}{l}\text { One participant was successful with } \\
\text { VP only; } 3 \text { participants required error } \\
\text { correction in addition to VP to reach } \\
\text { criterion. Participants typically had a }\end{array}$ \\
\hline
\end{tabular}


initially unsuccessful in learning a daily living skill using antecedent VP

\begin{tabular}{ll}
\hline Mechling, & If multi-step task completion \\
Ayers, & could effectively be taught \\
Bryant, \& & using CVM instructional \\
Foster, & technique. \\
(2014) &
\end{tabular}

\begin{tabular}{ll}
\hline Mechling et & To determine if adults with \\
al. (2014) & moderate ID will accurately \\
& complete multi-component \\
& tasks when using CVM as the \\
& method of prompting
\end{tabular}

Mechling et Determine if students with

al. (2008)

moderate ID could independently use VP on a portable DVD player when learning food preparation skills

3 adolescents with
moderate ID in addition
to dual diagnoses:
Autism (1);
Prader-Willi syndrome
(1); and Down
syndrome (1)

Four adults with Down

syndrome and moderate ID

$\begin{array}{ll}\begin{array}{l}\text { Multi-step cleaning } \\ \text { tasks: }\end{array} & \begin{array}{l}\text { Multiple probe } \\ \text { design across three } \\ \text { cleaning tasks, }\end{array} \\ \text { 1. Clean exercise bike } & \begin{array}{l}\text { replicated across } \\ \text { 2. Shampoo/vacuum } \\ \text { area rug }\end{array} \\ \text { three students }\end{array}$

counter surfaces

\section{Folding multiple}

sizes of towels

2. Sorting recycling

items

3. Preparing buffet

with multiple serving

stations

\section{Three young adults}

with moderate ID

Prepare the following

meals:

1. Grilled cheese

sandwich

2. Ham salad

3. Hamburger Helper

microwave singles multi-component

tasks

Multiple probe design across three cooking tasks and replicated across three participants correct response following the second viewing of the video clip.

All students showed growth in

percentage of steps completed correctly across all tasks, yet, difficulty and concerns were found. 1) One student could not stay in sync with the $\mathrm{VM}$, and 2) Students were more successful with certain.

CVM was effective for 3 of the 4

Multiple probe

participants across all three tasks, and effective for 1 participant while completing two of the three multi-component tasks.
All students effectively reached criterion across all tasks, requiring few sessions, when using the DVD player and receiving SLP instruction to correctly use functions on DVD player. Participants independently applied the VP instructions. Low percentages of errors were reported across all learners (5.4-7.8\%).

\begin{tabular}{ll}
\hline Mechling \& & Compare effectiveness of \\
Gustafson & using a static picture prompt \\
(2009) & vs. VP, when both are \\
& presented as antecedent \\
& visual prompts preceding \\
& completion of a cooking \\
& related motor skill \\
\hline
\end{tabular}
Stephens (2009) \& Gustafson (2009), Four young adults with moderate ID

Six young adults with moderate ID comparing VP and static pictures across multi-step tasks. Each system was evaluated in isolation.

Sigafoos et Evaluate the effectiveness of
al. (2006) VP when using a novel 3-step fading procedure to teach dish washing skills to adults with DD.

20 simple cooking related motor tasks that were represented by a single picture in a modified cookbook (e.g., "open rolls," "peel carrot," etc.)

Prepare 3 cooking
tasks.

Adapted
alternating
treatments design,
with baseline and
final treatment
conditions

All 6 participants obtained a higher percentage of corrects $($ mean $=82.6 \%$ ) with VP, in comparison to presentation of static picture prompts (mean of corrects $=46.7 \%$ ).

Adapted

alternating treatments design, final treatment conditions

$\begin{array}{ll}\text { Three adults with dual } & \text { Wash dishes used for } \\ \text { diagnoses of Autism } & \text { their snack (i.e., a cup, } \\ \text { and mild (1) or } & \text { plate, and spoon) }\end{array}$
Multiple baseline across subjects design. Baseline conditions were reintroduced place, and demonstrated an immediate

Mechling \& Extend the work of Mechling
with baseline and following first VP phase, then video fading procedure was introduced.

\begin{tabular}{|c|c|c|c|c|c|}
\hline Van & Compare effectiveness and & Three adolescents with & One domestic skill & \multirow{7}{*}{$\begin{array}{l}\text { Within subject } \\
\text { adapted alternating } \\
\text { treatments design }\end{array}$} & All 3 methods of instruction were \\
\hline Laarhoven \& & efficiency of 3 video-based & moderate ID; one & taught per instructional & & effective in increasing independence \\
\hline Van & instructional methods: 1) & participant also had a & condition: & & while decreasing prompting as \\
\hline \multirow{4}{*}{$\begin{array}{l}\text { Laarhoven-M } \\
\text { yers (2006) }\end{array}$} & VM/ rehearsal; 2) VM/ & diagnosis of autism & 1. Cooking a & & participants acquired daily living skills. \\
\hline & rehearsal + photo & & microwave pizza & & Both the video/In-vivo VP and \\
\hline & presentation during task & & 2. Folding clothes & & $\mathrm{VM} /$ rehearsal + photo were more \\
\hline & engagement; 3) Video & & 3. Washing a table & & efficient as measured by number of \\
\hline
\end{tabular}
with step-by-step VP procedure in increase in percentage of corrects during the process. 
rehearsal+ in-vivo VP during

task engagement. All

strategies were used in

conjunction with the SLP

Van Compare effectiveness of

Laarhoven et self-, other-, and subjective-

al. (2009)
VMs on teaching domestic

skills to adolescents with ID

$\begin{array}{ll}\text { Three adolescents with } & \begin{array}{l}\text { One daily living skill } \\ \text { taught across each } \\ \text { instructional condition: } \\ \text { 1. Cooking a hot dog in } \\ \text { the microwave } \\ \text { 2. Cleaning a bathroom } \\ \text { sink } \\ \text { 3. Using a screwdriver } \\ \text { to change batteries }\end{array}\end{array}$

sessions to criterion. Some prompting

was required to remain focused on

instructional materials.

\section{Results}

\subsection{Participants}

The 12 studies reviewed (see Table 1) included a total of 46 participants. All participants were adolescents or adults diagnosed with mild or moderate ID. Of those, 14 participants had a secondary diagnosis, such as Autism Spectrum Disorder (ASD), Asperger's, Down syndrome, Prader-Willi syndrome, and other health impairments (Cannella-Malone et al., 2006; Gardner \& Wolfe, 2015; Mechling, Ayers, Bryant et al., 2014; Sigafoos et al., 2006. Van Laarhoven \& Van Laarhoven-Myers, 2006).

\subsection{Video-Based Instruction}

The effectiveness of using video-based instruction to acquire a new daily living skill(s) was consistently measured across the literature. More than half of the reviewed research $(n=8)$ measured VP. Specifically, one study measured the effectiveness of VP in isolation (Mechling et al., 2008), two studies measured the effectiveness of VP when implemented with an error correction procedure (Gardner \& Wolfe, 2015; Goodson et al., 2007), one study evaluated VP when used with a 3-step fading procedure (Sigafoos et al., 2006), and two comparative studies measured the effectiveness of VP versus static picture prompts (Mechling \& Gustafson, 2009; Mechling \& Stephens, 2009). Additionally, two studies compared the efficacy of VP versus VM procedures (Cannella-Malone et al., 2006; Van Laarhoven \& Van Laarhoven-Myers, 2006). The effectiveness of VM was exclusively measured across the remaining four studies (Ayres \& Cihak, 2010; Mechling, Ayers, Bryant et al., 2014; Mechling, Ayres, Purrazzella et al., 2014; Van Laarhoven et al., 2009).

\subsection{Designs}

Seven studies used a multiple baseline or multiple probe design across behaviors/participants (Ayres \& Cihak, 2010; Gardner \& Wolfe, 2015; Goodson et al., 2007; Mechling, Ayers, Bryant et al., 2014; Mechling, Ayres, Purrazzella et al., 2014; Mechling et al., 2008; Sigafoos et al., 2006). Cannella-Malone et al. (2006) combined a multiple-probe across participants with an alternating treatment design, and researchers in four studies used an adapted alternating treatments design (Mechling \& Gustafson, 2009; Mechling \& Stephens, 2009; Van Laarhoven \& Van Laarhoven-Myers, 2006; Van Laarhoven et al., 2009).

\subsection{Targeted Skills}

Reviewed research specifically targeted the effectiveness of using video-based instruction to teach essential daily living skills. Food preparation was the most prevalent skill assessed $(n=7$; Ayres \& Cihak, 2010; Mechling, Ayres, Purrazzella et al., 2014; Mechling et al., 2008; Mechling \& Gustafson, 2009; Mechling \& Stephens, 2009; Van Laarhoven \& Van Laarhoven-Myers, 2006; Van Laarhoven et al., 2009). Within those studies, four of them additionally measured the effectiveness of VI on acquisition of other daily living skills (e.g., setting a table, folding, cleaning, changing batteries; Ayres \& Cihak, 2010; Mechling, Ayres, Purrazzella et al., 2014; Van Laarhoven \& Van Laarhoven-Myers, 2006; Van Laarhoven et al., 2009). Across reviewed studies, the effectiveness of VM or VP was measured on the following daily living skills: (a) setting the table (Ayres \& Cihak, 2010; Cannella-Malone, 2006; Goodson et al., 2007); (b) washing dishes (Gardner \& Wolfe, 2015; Sigafoos et al., 2006); (c) folding laundry 
(Mechling, Ayres, Purrazzella et al., 2014; Van Laarhoven \& Van Laarhoven-Myers, 2006); and (d) cleaning (Mechling, Ayers, Bryant et al., 2014; Van Laarhoven \& Van Laarhoven-Myers, 2006; Van Laarhoven et al., 2009). One study also included sorting recycled materials (Mechling, Ayres, Purrazzella et al., 2014), and another measured changing batteries in addition to other acquired skills (Van Laarhoven et al., 2009). All targeted skillsets were either completed in the home environment, or the goal was for individuals to generalize acquired daily living skills in the home setting. Thus, skill selection across reviewed literature was commonly premised on promoting everyday independent functioning for adolescents and adults with ID. Notable similarities were found in selected strategies and treatment effectiveness across comparable skills, yet differences were identified as well.

\subsection{Strategy Effectiveness}

VM and VP procedures yielded positive results on skill acquisition across reviewed research. Although not all participants reached criterion, skill growth was evidenced through increased percentages of correct responses and decreased reliance on staff (Gardner \& Wolfe, 2015; Mechling \& Stephens, 2009; Van Laarhoven \& Van Laarhoven-Myers, 2006). Researchers conclusively noted positive outcome effects in daily living skill attainment as a result of learning through a video-based instructional method. Specific details unique to VM and VP strategy effectiveness will follow.

\subsubsection{Video Modeling}

The reviewed literature consisted of studies using VM while teaching various daily living skills to adolescents and adults with mild or moderate ID. The observed viewpoint of video models varied (Van Laarhoven et al., 2009). In a comparative study, Van Laarhoven et al. (2009) examined self-, other-, and subjective- models while teaching daily living skills (e.g., cooking, cleaning, using a screwdriver) to young adults with moderate ID. Although the three variations effectively increased correct independent responses, "subjective" and "other" models resulted in greater acquisition, generalization, and maintenance of target skills compared to the "self" models (Van Laarhoven et al.). Correspondingly, three additional studies implemented VM from the "objective" perspective (Cannella-Malone et al., 2006; Mechling, Ayres, Purrazzella et al., 2014; Van Laarhoven \& Van Laarhoven-Myers, 2006), and participants in two studies viewed video models through a "subjective" lens (Ayres \& Cihak, 2010; Mechling, Ayres, Bryant et al., 2014). Of those, three studies followed the traditional VM procedural implementation (i.e., viewing video clip in its entirety prior to performing the task; Ayers \& Cihak, 2010; Cannella-Malone et al., 2006; Van Laarhoven \& Van Laarhoven-Myers, 2006), whereas, two studies applied the CVM method (i.e., continuous looping of the video model during task performance; Mechling, Ayers, Bryant et al., 2014; Mechling, Ayres, Purrazzella et al., 2014).

Through implementation of CVM, researchers assessed procedural effectiveness on both multi-component (e.g., folding towels of various sizes, sorting recycling items, preparing multiple serving stations for a buffet; Mechling, Ayres, Purrazzella et al., 2014) and multi-step (e.g., cleaning an exercise bike, shampooing an vacuuming a rug, cleaning kitchen counters; Mechling, Ayers, Bryant et al., 2014) daily living tasks. Using the continuous (looping) method and presenting the video models from both the subjective (Mechling, Ayers, Bryant et al., 2014) and objective viewpoints (Mechling, Ayres, Purrazzella et al., 2014), participants increased the percentage of steps completed correctly. However, one student relied on an error correction procedure that consisted of instructor modeling to successfully perform the target skills (Mechling, Ayres, Purrazzella et al., 2014). Following the embedded error correction procedure, task performance effectively increased. Overall, CVM provided learners with repeated model demonstrations of the desired performance without pauses or interruptions during the cyclical viewings. Nonetheless, participants showed difficulty independently keeping up with the pace of the model, which resulted in skipping essential steps of the task (Mechling, Ayers, Bryant et al., 2014; Mechling, Ayres, Purrazzella et al., 2014).

Ayres and Cihak (2010) used a unique variation of VM, referred to as computer-based video instruction. After viewing the video model on a computer, participants performed a step-by-step computer simulation before applying the learned task in the natural environment. This method resulted in all participants successfully reaching criterion (Ayres \& Cihak, 2010). Adding a supportive component to the traditional VM method was found to be beneficial across comparative research as well. For example, Van Laarhoven and Van Laarhoven-Myers (2006) compared three applications of VM used to teach daily living skills to adolescents with ID: (a) traditional VM implemented in isolation, (b) VM when paired with video prompting, and (c) VM combined with static picture prompts. The VM/VP and $\mathrm{VM}$ /picture conditions resulted in greater independent responding than VM alone (Van Laarhoven \& Van Laarhoven-Myers, 2006). This finding is consistent with that of Cannella-Malone et al. (2006), concluding the VM procedure was not very effective in teaching daily living skills to adults with developmental disabilities. Conversely, VP was found to effectively enhance skill acquisition among the same participants (Cannella-Malone et al., 2006). 


\subsubsection{Video Prompting}

In two studies, VP was implemented simultaneously with error correction procedures (Gardner \& Wolfe, 2015; Goodson et al., 2007). Daily living skills included a task analysis for washing dishes (Gardner \& Wolfe, 2015) and setting the table (Goodson et al., 2007). Procedural implementation of VP with the embedded error correction technique differed between the two studies. Initial verbal directives given by the instructor along with allotted wait time (e.g., 30 s) were consistent. However, Gardner and Wolfe (2015) used a system of least prompts (SLP) hierarchy. Hence, instructors prompted learners if they failed to complete the task within the given time (e.g., $30 \mathrm{~s}$ ) or if participants made an error after initial viewing of the VP. Conversely, Goodson et al. (2007) responded to unsuccessful task completion by initially replaying the video clip, followed by modeling the desired behavior, if needed. Implementation of VP with an embedded error correction procedure resulted in successful acquisition of daily living skills for individuals with ID (Gardner \& Wolfe, 2015; Goodson et al., 2007). Moreover, Gardner and Wolfe (2015) reported consistent increases in independent responding while the need and intensity of instructor prompts decreased.

Mechling et al. (2008) used the SLP error correction procedure, yet the method and purpose of implementation was very different compared to the latter. The SLP was used to increase the independent use of a portable DVD player during probe sessions, aiming to teach individuals with moderate ID to self-prompt. Thus, the SLP method was not implemented based on incorrect participant responses; instead the procedure was used to promote independent use of the prompting device. The effectiveness of using VP while learning cooking skills was measured in addition to changes in self-prompting abilities (Mechling et al., 2008). Viewing VP clips through a portable DVD player resulted in students efficiently reaching criterion on measured cooking tasks. However, some adult prompting was still required to effectively operate the DVD player (Mechling et al., 2008).

Three additional studies measured the effectiveness of VP where the procedure did not coincide with other instructional methods (Mechling \& Gustafson, 2009; Mechling \& Stephens, 2009; Sigafoos et al., 2006). Similar to the Mechling et al. (2008) research, two of these studies used a portable DVD player when presenting VP clips (Mechling \& Gustafson, 2009; Mechling \& Stephens, 2009), and one displayed the step-by-step task analysis through a mini computer (Sigafoos et al., 2006). Mechling and Stephens (2009) modified the buttons on the DVD player, providing learners with fewer options (e.g., start, pause, replay) when viewing video clips. Mechling and Gustafson (2009) embedded a verbal directive in the model to "pause" the DVD player at the conclusion of each successive video step. In contrast, Sigafoos et al. (2006) relied on instructors to operate the mini computer in addition to providing verbal prompts at the onset and conclusion of each step. Aside from the noted differences in the use and expectations of VP devices, all three studies taught various essential kitchen related tasks to individuals with mild or moderate ID. Food preparation skills (e.g., making ravioli, peeling a carrot, preparing hot chocolate) were taught across two of the studies (Mechling \& Gustafson, 2009; Mechling \& Stephens, 2009), and Sigafoos et al. (2006) used VP to teach dish washing skills, before fading the prompt procedure. Overall, data revealed increased performance in target skills across participants (Mechling \& Gustafson, 2009; Mechling \& Stephens, 2009; Sigafoos et al., 2006). Sigafoos et al. (2006) reported immediate increases in percentages of correct responding as a result of VP. Moreover, comparative research showed VP to be a more effective instructional method than using static picture prompts when acquiring cooking skills in young adults with moderate ID (Mechling \& Gustafson, 2009; Mechling \& Stephens, 2009).

\subsection{Maintenance and Generalization Data}

Researchers in six studies reported maintenance data yet did not include skill generalization (Ayres \& Cihak, 2010; Gardner \& Wolfe, 2015; Mechling, Ayres, Purrazzella et al., 2008; Mechling \& Gustafson, 2009; Mechling, Ayres, Bryant et al., 2014; Sigafoos et al., 2006). Investigators in two additional studies effectively measured both maintenance and generalization data across acquired skills (Van Laarhoven \& Van Laarhoven-Myers, 2006; Van Laarhoven et al., 2009). In examining reported maintenance data, three data collection themes emerged. The first theme consists of continued use of VP through a portable device during maintenance probes (Mechling, Ayres, Bryang et al., 2014; Mechling et al., 2008). While the SLP was not implemented during maintenance sessions (Mechling et al., 2008), a self-prompting device (e.g., portable DVD player) was accessible to participants. The second theme includes initial withdrawal of video-based instruction during maintenance sessions (Ayres \& Cihak, 2010; Gardner \& Wolfe, 2015). Subsequent to deteriorated performance, a booster session occurred, utilizing the prompting device. Maintenance data collection followed, and revealed maintained skill acquisition following the booster (Ayres \& Cihak, 2010; Gardner \& Wolfe, 2015). The third theme entails pure withdrawal of video-based instruction during maintenance sessions (Mechling \& Gustfson, 2009; Sigafoos et al., 2006; Van Laarhoven \& Van 
Laarhoven-Myers, 2006; Van Laarhoven et al., 2009). In comparison to the latter, maintenance data using withdrawal of video-based instruction only, lacking booster sessions. Thus, data revealed lower levels of correct independent responding across measured daily living skills. Furthermore, in a comparative study, Mechling and Gustafson (2009) found VP to be more conducive to independent functioning than using static picture prompts when teaching cooking tasks to adolescents with moderate ID. However, only one out of six participants successfully maintained the learned skills once the video prompts were removed (Mechling \& Gustafson, 2009). Sigafoos et al. (2006) implemented a three-step fading procedure to follow VP when teaching dishwashing skills to adults with mild or moderate ID. This chunking process entailed presenting participants with an increasing number of steps in each prompt (e.g., combining steps 1-4), before the video clip presented the skillset in its entirety. Subsequently, the video device was completely removed. The fading procedure was effective, and promoted a seamless transition for two of the three participants, yet one student struggled with decreasing prompts, which was evident at the initial chunking phase (Sigafoos et al., 2006). Sigafoos et al. (2006) implemented the fading procedure with the intent to systematically decrease prompt dependency, yet no generalization data were collected.

Of the reviewed research, two studies measured skill generalization across environments (settings not used during instruction; Van Laarhoven \& Van Laarhoven-Myers, 2006; Van Laarhoven et al., 2009). Participants successfully generalized acquired daily living skills, and data showed specific instructional methods used to promote greater generalization. For example, when comparing VM and VM/picture prompts, increased scores were demonstrated in the VM/VP condition (Van Laarhoven \& Van Laarhoven-Myers, 2006). Moreover, in examining the perspective of the model, "other" and "subjective" viewpoints promoted greater generalization in comparison to "self" models (Van Laarhoven et al., 2009). Van Laarhoven and Van Laarhoven-Myers (2006) found stimulus/response relationships might have been influential to generalization data. While participants generalized all acquired skills, microwaving a pizza had more predictable successive steps in comparison to cleaning or folding laundry and also resulted in higher independent responding scores during generalization sessions (Van Laarhoven \& Van Laarhoven-Myers, 2006).

\section{Discussion}

The purpose of this review of the literature is to evaluate the effectiveness of video-based instruction (e.g., VM, VP) on skill acquisition, generalization, and maintenance of daily living skills among adolescents and adults with mild or moderate ID. Each of the 12 reviewed empirical articles reported positive results when applying VP or VM to learn essential daily living skills. The majority of learners demonstrated rapid growth in task performance when the independent variable (e.g., VM, VP) was introduced. Doing so prompted the transfer of stimulus control from the instructor to the learner, promoting increased independent functioning. Notable methodological differences exist between VM and VP, which could influence procedural effectiveness for learners. Hence, selection of a video-based instructional technique should be individualized with learners' needs and unique abilities considered.

Viewing a skillset in its entirety during presentation of a VM clip is quite demanding of the learners' attention (Van Laarhoven \& Van Laarhoven-Myers, 2006). Additionally, he or she [the learner] is required to remember all of the sequential steps needed to appropriately perform the entire task. Reviewed research on VM provided one or two opportunities for participants to correctly apply acquired skills, which may not be enough trials for some learners. Application of CVM, on the other hand, presents the video model in a looping fashion, with the intent to continuously provide learners with an uninterrupted and repetitive demonstration of the expected skillset (Mechling, Ayers, Bryan, et al., 2014). However, participants had similar attention related difficulties with CMV as those using the traditional VM approach. Additionally, participants using CVM may struggle keeping up with the pace of the model, as the video plays simultaneously while the learner is expected to apply the behavior in the natural environment. Consequently, learners may omit essential steps necessary for successful task completion. Thus, CVM is not recommended for teaching chained tasks to individuals with ID (Mechling, Ayres, Purrazzella, et al. 2014).

The VP procedure breaks tasks down to individual, sequential steps, enabling learners to immediately apply each skill after viewing the model. This may be suitable for learners with shorter attention spans or those who have difficulty remembering the successive steps of a task. Moreover, VP data presents detailed acquisition results, making it clear which specific steps of a skill require more training. Both VM and VP require learners to display a certain amount of autonomy to successfully implement the self-prompting procedures independently.

Along with positive learner outcomes resulting from VI, there are notable challenges as well. According to Sigafoos et al. (2006), learners using VM and VP procedures may show signs of prompt dependency and struggle to successfully fade the prompt. However, using technology to promote self-prompting rather than becoming prompt dependent on instructional staff is extremely valuable with the ID population. 
Maintenance data across studies showed withdrawal of video-based instruction to result in decreased performance (Ayres \& Cihak, 2010; Gardner \& Wolfe, 2015). Sigafoos et al. (2006) successfully implemented a 3-step fading procedure that resembled VP slowly progressing to VM before complete removal of the prompt. Subsequent to the fading procedure, most participants effectively maintained newly learned daily living skills.

Learners with ID often struggle to effectively generalize newly learned skills (Van Laarhoven \& Van Laarhoven-Myers, 2006). Generalization data were only reported in two studies (Van Laarhoven \& Van Laarhoven-Myers, 2006; Van Laarhoven et al., 2009), yet the need was noted as a study limitation and future implication across nearly all of the reviewed literature. Of the studies under review that included generalization probes, stimulus/response relationships were found to possibly influence data by presenting clear successive steps toward task completion (Van Laarhoven \& Van Laarhoven-Myers, 2006). The desirability and reinforcement of completing the task itself was also reported to affect generalization data. For example, positive learning outcomes were more prevalent when teaching food related skills when participants were able to eat the meal after preparing it (Ayres \& Cihak, 2010; Van Laarhoven \& Van Laarhoven-Myers, 2006).

\section{Future Implications}

Findings from this literature review lend future research and practical implications. First, when measuring the effectiveness of any form of video-based instruction, it is imperative to familiarize participants with the electronic device. If, for example, the learner has difficulty understanding how to use basic functions needed to properly view the videos, he or she will continue to be dependent on instructional staff during intervention sessions. Second, findings showed increased rates of acquisition, generalization, and maintenance when completing desirable food-related tasks (Ayres \& Cihak, 2010; Van Laarhoven \& Van Laarhoven-Myers, 2006). Correspondingly, future research should take personal preferences into consideration upon skill selection. Third, a replication of Sigafoos et al. (2006) is recommended, implementing the 3 -step fading procedure after teaching daily living skills to individuals with ID. Given the unique needs of individuals with mild or moderate ID in terms of maintaining and generalizing skills, a systematic prompt fading procedure seems more appropriate than abrupt removal of prompts. Finally, future research should include generalization probes, as the generalizability of acquired skills demonstrates mastery. With a goal to promote independent functioning in individuals with ID, researchers must focus on how to effectively increase autonomous functioning through technology with this capable population of learners.

Practitioners are recommended to use video-based instructional procedures when teaching adolescents and adults with mild and moderate ID. Selection of the unique method should be based on both individual abilities in addition to the skills being taught. Individuals who require more explicit instructions with clear expectations would likely benefit from VP as opposed to VM. Employing VP would enable such learners to complete chained tasks, previewing a model prior to applying each synchronized step during task completion. Conversely, VM would be an appropriate instructional technique for learners with greater attention spans and stronger memory abilities. Regardless of the selected strategy, all video-based instructional methods should be used to prompt students, with a goal to require little to no reliance on instructional staff. Subsequent to mastery of the target skill, practitioners should begin fading the use of the instructional device as the learner demonstrates maintained skill acquisition.

\section{Conclusion}

VM and VP have been shown empirically to promote acquisition of daily living skills among adolescents and adults with mild or moderate ID (Mechling et al., 2008; Mechling \& Stephens, 2009; Van Laarhoven et al., 2009). This review of the literature found implementation of VI procedures to result in rapid skill attainment across participants while simultaneously promoting independent functioning. These findings are critical to the field, as empirical research demonstrates a need to increase postsecondary independence among young adults with ID (Carnahan, Hume, Clark, \& Borders, 2009; Sigafoos et al., 2005; Taber-Doughty, Bouck, Tom, Jasper, Flanagan, \& Bassette, 2011). Further, this review supports the use of both VM and VP as instructional procedures to consider when teaching adolescents and young adults with mild or moderate ID. It should be noted, however, that while generalization data demonstrated successful learner outcomes, only two studies in this review included generalization measures (Van Laarhoven \& Van Laarhoven-Myers, 2006; Van Laarhoven et al., 2009). Maintenance data were more frequently reported across the literature, yet discrepancies were presented in data collection methods.

In sum, this review found VM and VP to enhance skill acquisition, generalization, and maintenance of daily living skills among adolescents and young adults with mild or moderate ID. Students with ID tend to require repetition and practice when learning a new skill (Ayres \& Cihak, 2010), and VM and VP procedures provide repetition and practice in the natural environment. Additionally, both VM and VP procedures hold promise in shifting stimulus control to the learner, promoting independence in the application of essential daily living skills. These findings 
should be taken into consideration when selecting instructional techniques to use when teaching students with ID, especially during secondary and postsecondary years. Furthermore, in addition to practical implications, this review lends suggestions for future research measuring the effectiveness of video-based instruction among learners with ID.

\section{References}

Alberto, P. A., Cihak, D. F., \& Gama, R. I. (2005). Use of static picture prompts versus video modeling during simulation instruction. Research in Developmental Disabilities, 26, 327-339. https://doi.org/10.1016/j.ridd.2004.11.002

Ault, M. J., Gast, D. L., \& Wolery, M. (1988). Comparison of progressive and constant time-delay procedures in teaching community-sign word reading. American Journal on Mental Retardation, 93(1), 44-56.

Ayres, K., \& Cihak, D. (2010). Computer- and video-based instruction of food-preparation skills: acquisition, generalization, and maintenance. Intellectual and Developmental Disabilities, 48, 195-208. https://doi.org/10.1352/1944-7558-48.3.195

Banda, D. R., Dogoe, M. S., \& Matuszny, R. M. (2011). Review of video prompting studies with persons with developmental disabilities. Education and Training in Developmental Disabilities, 46, 514-527. Retrieved from http://eric.ed.gov/?id=EJ950770

Bouck, E. C. (2014). The postschool outcomes of students with mild intellectual disability: Does it get better with time?. Journal of Intellectual Disability Research, 58, 534-548. https://doi.org/10.111/jir.12051

Cannella-Malone, H., Sigafoos, J., O’Reily, M., de la Cruz, B., Edrisinha, C., \& Lancioni, G. E. (2006). Comparing video prompting to video modeling for teaching daily living skills to six adults with developmental disabilities. Education and Training in Developmental Disabilities, 41, 344-356. Retrieved from http://www.jstor.org/stable/23879661

Carnahan, C. R., Hume, K., Clarke, L., \& Borders, C. (2009). Using structured work systems to promote independence and engagement for students with autism spectrum disorders. Teaching Exceptional Children, 41(4), 6-14. 6etrieved from http://www.autismoutreach.ca/sites/default/files/3_02_structured_work_systems.pdf

Gardner, S. J., \& Wolfe, P. S. (2015). Teaching students with developmental disabilities daily living skills using point-of-view modeling plus video prompting with error correction. Focus on Autism and Other Developmental Disabilities, 30, 195-207. https://doi.org/10.1177/1088357614547810

Gast, D. L., Ault, M. J., Wolery, M., Doyle, P. M., \& Belanger, S. (1988). Comparison of Constant Time Delay and the System of Least Prompts in Teaching Sight Word Reading to Students with Moderate Retardation. Education and Training in Mental Retardation, 23(2), 117-128. Retrieved from http://www.jstor.org/stable/23878435

Goodson, J., Sigafoos, J., O’Reilly, M., Cannella, H., \& Lancioni, G. E. (2007). Evaluation of a video-based error correction procedure for teaching a domestic skill to individuals with developmental disabilities. Research in Developmental Disabilities, 28, 458-467. https://doi.org/10.1016/j.ridd.2006.06.002

Graves, T. B., Collins, B. C., Schuster, J. W., \& Kleinert, H. (2005). Using video prompting to teach cooking skills to secondary students with moderate disabilities. Education and Training in Developmental Disabilities, 40(1), 34-46. Retrieved from http://www.jstor.org/stable/23879770

Grigal, M., Hart, D., \& Migliore, A. (2011). Comparing the transition planning, postsecondary education, and employment outcomes of students with intellectual and other disabilities. Career Development for Exceptional Individuals, 34(1), 1-14. https://doi.org/10.1177/0885728811399091

Individuals with Disabilities Education Improvement Act of 2004, PL 108-446, 20 U.S.C. $\S \S 1400$ et seq. (2004).

Li, J., Bassett, D. S., \& Hutchinson, S. R. (2009). Secondary special educators' transition involvement. Journal of Intellectual and Developmental Disability, 34(2), 163-172. https://doi.org/10.1080/13668250902849113

Luftig, R. L., \& Muthert, D. (2005). Patterns of employment and independent living of adult graduates with learning disabilities and mental retardation of an inclusionary high school vocational program. Research in Developmental Disabilities, 26, 317-325. https://doi.org/10.1016/j.ridd.2003.08.001 
Mechling, L. C., \& Gustafson, M. (2009). Comparison of the effects of static picture and video prompting on completion of cooking related tasks by students with moderate intellectual disabilities. Exceptionality, 17, 103-116. https://doi.org/10.1080/09362830902805889

Mechling, L. C., \& Stephens, E. (2009). Comparison of self-prompting of cooking skills via picture-based cookbooks and video recipes. Education and Training in Developmental Disabilities, 44, 218-236. Retrieved from: http://www.jstor.org/stable/242333496

Mechling, L. C. (2008). High tech cooking: A literature review of evolving technologies for teaching a functional skill. Education and Training in Developmental Disabilities, 43, 474-485. Retrieved from http://www.jstor.org/stable/23879677

Mechling, L. C., Ayres, K. M., Bryant, K. J., \& Foster, A. L. (2014). Continuous video modeling to assist with completion of multi-step home living tasks by young adults with moderate intellectual disability. Education and Training in Developmental Disabilities, 49, 368-380. Retrieved from http://eric.ed.gov/?id=EJ1034472

Mechling, L. C., Ayres, K. M., Purrazzella, K., \& Purrazzella, K. (2014). Continuous video modeling to prompt completion of multi-component tasks by adults with moderate intellectual disability. Education and Training in Developmental Disabilities, 49(1), 3-16. Retrieved from http://eric.ed.gov/?id=EJ1016609

Mechling, L. C., Gast, D. L., \& Fields, E. A. (2008). Evaluation of a portable dvd player and system of least prompts to self-prompt cooking task completion by young adults with moderate intellectual disabilities. The Journal of Special Education, 42, 179-190. https://doi.org/10.1177/0022466907313348

Mechling, L. C., Gast, D. L., \& Seid, N. H. (2010). Evaluation of a personal digital assistant as a self-prompting device for increasing multi-step task completion by students with moderate intellectual disabilities. Education and Training in Autism and Developmental Disabilities, 45, 422-439. Retrieved from http://eric.ed.gov/?id=EJ906275

Sigafoos, J., O'Reilly, M., Cannella, H., Edrisinha, C., Cruz, B., Upadhyaya, M., ... Young, D. (2006). Evaluation of a video prompting and fading procedure for teaching dish washing skills to adults with developmental disabilities. Journal of Behavioral Education, 16(2), 93-109. https://doi.org/10.1007/s10864-006-9004-z

Sigafoos, J., O'Reilly, M., Cannella, H., Upadyaya, M., Edrisinha, C., Lancioni, G. E., ... David, Y. (2005). Computer-presented video prompting for teaching microwave oven use to three adults with developmental disabilities. Journal of Behavioral Education, 14, 189-201. https://doi.org/10.1007/s10864-005-6297-2

Swain, R., Lane, J. D., \& Gast, D. L. (2015). Comparison of constant time delay and simultaneous prompting procedures: Teaching functional sight words to students with intellectual disabilities and autism spectrum disorder. Journal of Behavioral Education, 24, 210-229. https://doi.org/10.1007/s10864-014-9209-5

Taber-Doughty, T., Bouck, E. C., Tom, K., Jasper, A. D., Flanagan, S. M., \& Bassette, L. (2011). Video modeling and prompting: A comparison of two strategies for teaching cooking skills to students with mild intellectual disabilities. Education and Training in Autism and Developmental Disabilities, 46, 499-513. Retrieved from http://eric.ed.gov/?id=EJ950769

Van Laarhoven, T., \& Van Laarhoven-Myers, T. (2006). Comparison of three video-based instructional procedures for teaching daily living skills to persons with developmental disabilities. Education and Training in Developmental Disabilities, 41, 365-381. Retrieved from: http://www.jstor.org/stable/23879663

Van Laarhoven, T., Zurita, L. M., Johnson, J. W., Grider, K. M., \& Grider, K. L. (2009). Comparison, of self, other, and subjective video models for teaching daily living skills to individuals with developmental disabilities. Education and Training in Developmental Disabilities, 44, 509-522. Retrieved from http://eric.ed.gov/?id=EJ883886 